\title{
Human Resource Management according to the Characteristics of Beauty Service Workers
}

\author{
Jung-Eun Park ${ }^{1}$, Ae-jin Yoo ${ }^{2}$, Eun-Jun Park ${ }^{1 *}$ \\ ${ }^{1}$ Department of Hair and Makeup Design, Seokyeong University, Seoul, Korea \\ ${ }^{2}$ Department of Health Industry, Sookmyung Women's University, Seoul, Korea
}

\author{
*Corresponding author: Eun-Jun Park, \\ Department of Hair and Makeup Design, \\ Seokyeong University, 124 Seogyeong-ro, \\ Seongbuk-gu, Seoul 02713, Korea \\ Tel.: +82 29457846 \\ Fax: +82 29457846 \\ Email: ayamdream@hanmail.net
}

Received June 10, 2019

Revised September 1, 2019

Accepted September 9, 2019

Published September 30, 2019

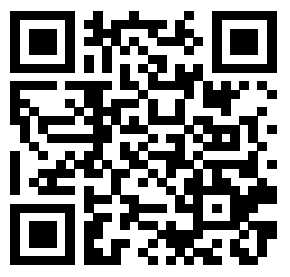

\begin{abstract}
Purpose: The present study investigates human resource management in the beauty service industry based the characteristics of workers. Methods: Data were collected from the beauty service industry and analyzed using Statistical Package for the Social Sciences (SPSS) 22.0. Frequency analysis, factor analysis, reliability analysis, independent sample -test, and one-way ANOVA were used for data analysis. Results: There were significant differences in human resource management based on gender, age, marital status, education, position, salary, work experience, company type, number of employees, and specialty. Conclusion: The study results can be used as basic data for the development of the beauty service industry. In the beauty service industry, systematic human resource management should be based on the characteristics of workers and be planned and managed to achieve the organizations goals.
\end{abstract}

Keywords: Beauty, Service, Human resource management, Beauty service workers, Characteristics

\section{Introduction}

현대사회에는 조직의 목표달성을 이루기 위하여 그 중심에 있 는 조직원들의 인적자원관리에 관심을 집중하고 있는 추세이다.

인적자원관리란 여러 가지의 인적자원활동들로 구성되어 있으 며(Kim \& Bae, 2006), 전략적 인적자원관리는 종사자의 조직애 착과 직무몰입을 증대시켜 직무수행역량을 강화하고 종사자의 이 직의도를 약화시킨다(Song et al., 2016). 이처럼 인적자원관리 는 가장 기본적이면서도 중요한 요소이며, 조직에 가치를 부여하 고 지속적인 조직의 경쟁우위를 창출하는 자원이라고 할 수 있다 (Na, 2010).

인적자원관리와 관련된 선행 연구를 살펴보면 $\mathrm{Bae} \mathrm{\&} \mathrm{Sa}$ (2003)는 인적자원관리와 조직성과에 대한 실증연구를 통해 인적 자원관리 시스템이 조직의 성과에 중요한 영향 요인임을 증명하였 고, Chae \& Kim (2019)는 조직수준에서의 자원기반이론을 토대 로 전략적 인적자원관리가 경영성과에 미치는 영향을 연구하여 전
략적 인적자원관리가 경영성과에 유의미한 정(+)의 영향을 미치 는 것을 확인하였다. Chang (2018)은 공정성 중시 인적자원관리 가 성 평등 조직문화에 미치는 영향을 연구하여 공정성 중시의 인 적자원관리는 성 평등 조직문화에 긍정적인 영향을 미치는 것을 확인하였으며, Park \& Cha (2018)는 인적자원관리 제도 중에서 평가보상제도 및 교육훈련제도에 대한 개별 종업원들의 인식이 개 인의 창의적 성과에 미치는 영향을 연구하여 교육훈련제도에 대 한 긍정적인 인식은 창의적 성과와 긍정적 관계를 보이는 것을 확 인하였다. Yoo \& Kim (2012)는 헌신형 인적자원관리와 기업성과 의 관계를 연구하여 헌신형 인적자원관리 시스템 구성요소와 시 스템은 기업성과에 모두 정(+)의 영향을 미치는 것을 확인하였으 며, Ha \& Shim (2013)은 고몰입형 인적자원관리와 경영성과 간 의 관계에 관한 연구를 하여 고몰입형 인적자원관리가 각각 활용 과 탐험에 정(+)의 영향을 주는 것을 확인하였다.

이처럼 인적자원관리에 관한 많은 연구들이 선행되어왔지만 미 용서비스업 종사자의 특성을 고려한 인적자원관리 연구는 아직 미 
비한 실정이다.

이에 본 연구는 미용서비스업 종사자의 특성에 따른 인적자원 관리의 차이를 알아보고 향후 미용서비스업에서의 인적자원관리 방향을 제시하고 효과적인 경영전략을 수립하는데 기초자료를 제 공하는데 목적이 있다.

\section{Methods}

\section{1. 연구대상자}

본 연구의 조사대상은 미용종사자를 대상으로 설정하였다. 2016년 5월 4일부터 2016년 6월 20일까지 실시되었고 총 730부

Table 1. General characteristics of participants

\begin{tabular}{|c|c|c|c|}
\hline \multirow{2}{*}{ Items } & & \multicolumn{2}{|c|}{ Total } \\
\hline & & Frequency $(\mathrm{N})$ & Percentage (\%) \\
\hline \multirow{2}{*}{ Gender } & Men & 84 & 12.0 \\
\hline & Women & 616 & 88.0 \\
\hline \multirow{5}{*}{ Age } & Teenager & 12 & 1.7 \\
\hline & $20 s$ & 535 & 76.4 \\
\hline & $30 \mathrm{~s}$ & 101 & 14.4 \\
\hline & $40 \mathrm{~s}$ & 43 & 6.1 \\
\hline & 50 s or older & 9 & 1.3 \\
\hline \multirow{3}{*}{ Marital status } & Single & 599 & 85.6 \\
\hline & Married & 93 & 13.3 \\
\hline & Divorced & 8 & 1.1 \\
\hline \multirow{4}{*}{ Education level } & Graduated from high school & 103 & 14.7 \\
\hline & Currently attending or graduated from college & 185 & 26.4 \\
\hline & Currently attending or graduated from university & 356 & 50.9 \\
\hline & Currently attending or graduated from graduate school & 56 & 8.0 \\
\hline \multirow{5}{*}{ Post } & Intern (assistant) & 337 & 48.1 \\
\hline & Designer (working- level) & 237 & 33.9 \\
\hline & Director (branch representative) & 50 & 7.1 \\
\hline & Chairman (representative) & 48 & 6.9 \\
\hline & Manager & 28 & 4.0 \\
\hline \multirow{3}{*}{ Type of wage } & Wage & 480 & 68.6 \\
\hline & Incentive & 169 & 24.1 \\
\hline & Others & 51 & 7.3 \\
\hline \multirow{5}{*}{ Beauty career } & 3 years or less & 431 & 61.6 \\
\hline & $4-6$ years & 121 & 17.3 \\
\hline & $7-9$ years & 67 & 9.6 \\
\hline & $10-12$ years & 33 & 4.7 \\
\hline & 13 years or more & 48 & 6.9 \\
\hline \multirow{3}{*}{ Type of company } & Franchise & 404 & 57.7 \\
\hline & Private enterprise & 269 & 38.4 \\
\hline & Others & 27 & 3.9 \\
\hline \multirow{5}{*}{ No. of employees } & 5 persons or less & 184 & 26.3 \\
\hline & $6-10$ persons & 241 & 34.4 \\
\hline & $11-15$ persons & 160 & 22.9 \\
\hline & $16-20$ persons & 49 & 7.0 \\
\hline & 21 persons or more & 66 & 9.4 \\
\hline \multirow{5}{*}{ Beauty field } & Hair & 504 & 72.0 \\
\hline & Makeup & 24 & 3.4 \\
\hline & Skin care & 122 & 17.4 \\
\hline & Nail art & 28 & 4.0 \\
\hline & Others & 22 & 3.1 \\
\hline Total & & 700 & 100.0 \\
\hline
\end{tabular}


의 설문지를 배포하여 700 부가 최종 분석 자료로 사용되었다.

\section{2. 자료처리 및 분석}

수집된 자료는 SPSS 22.0 프로그램을 활용하여 빈도분석, 요 인분석, 신뢰도분석, 독립표본 $t$-test, 일원변량분석(one way ANOVA)을 하였다.

\section{Results and Discussion}

\section{1. 조사대상의 일반적 특성}

조사대상의 일반적 특성을 알아본 결과는 Table 1 과 같다. 성별 은 남성 $12.0 \%$, 여성 $88.0 \%$ 로 여성이 높게 나타났다. 이는 Park (2018)의 연구에서 남성보다 여성의 비율이 매우 높게 나타난 결

Table 2. Dimensions of human resource management

\begin{tabular}{|c|c|c|c|c|}
\hline \multirow{2}{*}{$\begin{array}{l}\text { Questions related to human resources } \\
\text { management }\end{array}$} & Factor 1 & Factor 2 & Factor 3 & Factor 4 \\
\hline & $\begin{array}{c}\text { Education } \\
\text { management }\end{array}$ & $\begin{array}{c}\text { Work } \\
\text { management }\end{array}$ & $\begin{array}{c}\text { Compensation } \\
\text { management }\end{array}$ & $\begin{array}{l}\text { Employment } \\
\text { management }\end{array}$ \\
\hline \multicolumn{5}{|l|}{ My company offers employees } \\
\hline $\begin{array}{l}\text { opportunities for various education and } \\
\text { training programs in connection with } \\
\text { work. }\end{array}$ & 0.814 & 0.198 & 0.210 & 0.212 \\
\hline $\begin{array}{l}\text { My company makes much investment in } \\
\text { education and training of employees. } \\
\text { My companies provide employees with }\end{array}$ & 0.810 & 0.215 & 0.154 & 0.248 \\
\hline $\begin{array}{l}\text { longer hours of education and training, } \\
\text { compared to other companies in the } \\
\text { same industry. }\end{array}$ & 0.791 & 0.208 & 0.239 & 0.201 \\
\hline $\begin{array}{l}\text { My company has a systematic education } \\
\text { and training program which employees } \\
\text { can participate in. }\end{array}$ & 0.765 & 0.182 & 0.166 & 0.285 \\
\hline $\begin{array}{l}\text { Employees of my company participate } \\
\text { extensively in decision-making and } \\
\text { problem-solving processes related to } \\
\text { their work and working environment. } \\
\text { My company devolves authorities }\end{array}$ & 0.147 & 0.812 & 0.248 & 0.152 \\
\hline $\begin{array}{l}\text { and responsibilities extensively to } \\
\text { employees. }\end{array}$ & 0.152 & 0.811 & 0.179 & 0.141 \\
\hline $\begin{array}{l}\text { My company empowers employees } \\
\text { greatly, giving them much discretion. } \\
\text { My company introduces and operates }\end{array}$ & 0.121 & 0.731 & 0.376 & 0.176 \\
\hline $\begin{array}{l}\text { a team system actively for effective } \\
\text { performance of work. } \\
\text { In my company, feedback and coaching }\end{array}$ & 0.301 & 0.682 & 0.192 & 0.119 \\
\hline $\begin{array}{l}\text { occur among superiors/colleagues } \\
\text { smoothly. }\end{array}$ & 0.346 & 0.554 & 0.351 & 0.180 \\
\hline $\begin{array}{l}\text { In my company, wage determination } \\
\text { criteria are reasonable, transparent, and } \\
\text { fair. } \\
\text { My company pays wages relatively }\end{array}$ & 0.192 & 0.291 & 0.805 & 0.179 \\
\hline $\begin{array}{l}\text { higher than those of other companies in } \\
\text { the same industry. }\end{array}$ & 0.172 & 0.182 & 0.801 & 0.232 \\
\hline $\begin{array}{l}\text { I am paid a fair wage for the efforts that } \\
\text { I am making. }\end{array}$ & 0.199 & 0.310 & 0.776 & 0.112 \\
\hline $\begin{array}{l}\text { My company is operating a system that } \\
\text { distributes company profits to employees } \\
\text { (collective performance-relayed pay } \\
\text { system, profit-sharing system, etc.). }\end{array}$ & 0.234 & 0.316 & 0.735 & 0.169 \\
\hline $\begin{array}{l}\text { My company has proper screening } \\
\text { procedures such as tests, interviews, } \\
\text { etc., for employment. } \\
\text { My company sets forth clear selection }\end{array}$ & 0.170 & 0.082 & 0.103 & 0.839 \\
\hline $\begin{array}{l}\text { My company sets forth clear selection } \\
\text { criteria related to skill and ability for } \\
\text { employment. }\end{array}$ & 0.247 & 0.128 & 0.178 & 0.783 \\
\hline $\begin{array}{l}\text { My company considers skills and } \\
\text { attitude important for employment. } \\
\text { My company invests much time and }\end{array}$ & 0.205 & 0.251 & 0.147 & 0.714 \\
\hline $\begin{array}{l}\text { financial resources in the screening } \\
\text { process in order to select excellent } \\
\text { candidates. }\end{array}$ & 0.362 & 0.184 & 0.309 & 0.623 \\
\hline Unique value & 3. 222 & 3.219 & 3.138 & 2.690 \\
\hline Explained variance (\%) & 18.955 & 18.936 & 18.458 & 15.824 \\
\hline Cumulative variance (\%) & 18.955 & 37.891 & 56.349 & 72.173 \\
\hline Reliability coefficient (Cronbach's $\alpha$ ) & 0.900 & 0.870 & 0.893 & 0.834 \\
\hline
\end{tabular}


과와 일치하며 아직까지 미용서비스업에 종사하는 종사자들 중 여 성이 많은 비율을 차지하고 있다는 것을 보여준다. 연령은 10 대 $1.7 \%, 20$ 대 $76.4 \%, 30$ 대 $14.4 \%, 40$ 대 $6.1 \%, 50$ 대 이상 $1.3 \%$ 로 20 대가 가장 높게 나타났다. 결혼여부의 경우 미혼 $85.6 \%$, 기혼 $13.3 \%$, 이혼 $1.1 \%$ 로 미혼이 가장 높게 나타났다. 학력을 알아본 결과 고등학교 졸업 $14.7 \%$, 전문대학 재학/졸업 $26.4 \%$, 대학교 재학/졸업 $50.9 \%$, 대학원 재학/졸업 $8.0 \%$ 로 대학교 재학/졸업이 가장 높게 나타났다. 이는 Lim \& Park (2017)의 연구에서 대학 교(재학생포함)의 비율이 가장 높게 나타난 결과와 일치하며 과거
에 비해 미용서비스업에 종사하는 종사자들의 학력이 높아지고 있 음을 의미한다. 직급은 인턴(어시스트) $48.1 \%$, 디자이너(실무자) $33.9 \%$, 실장(점장) $7.1 \%$, 원장(대표) $6.9 \%$, 매니저 $4.0 \%$ 로 인 턴(어시스트)가 가장 높게 나타났다. 급여형태를 알아본 결과 급 여 $68.6 \%$, 인센티브 $24.1 \%$, 기타 $7.3 \%$ 로 급여가 가장 높게 나타 났다. 미용경력은 3년 이하 $61.6 \%, 4-6$ 년 $17.3 \%, 7-9$ 년 9.6\%, 10-12년 4.7\%, 13년 이상 6.9\%로 3년 이하가 가장 높게 나타났 다. 회사형태로는 프랜차이즈 $57.7 \%$, 개인 $38.4 \%$, 기타 $3.9 \%$ 로 프랜차이즈가 가장 높게 나타났으며, 직원 수는 5 명 이하 $26.3 \%$,

Table 3. Differences in human resource management by gender

\begin{tabular}{|c|c|c|c|c|c|}
\hline Gender & & & $M$ & S.D. & $t$-value $(p)$ \\
\hline \multirow{8}{*}{$\begin{array}{l}\text { Human resources } \\
\text { management }\end{array}$} & \multirow{2}{*}{ Education management } & Men & 3.68 & 0.811 & \multirow{2}{*}{1.624} \\
\hline & & Women & 3.53 & 0.828 & \\
\hline & \multirow{2}{*}{ Work management } & Men & 3.66 & 0.686 & \multirow{2}{*}{$3.299^{* *}$} \\
\hline & & Women & 3.37 & 0.763 & \\
\hline & \multirow{2}{*}{ Compensation management } & Men & 3.42 & 0.785 & \multirow{2}{*}{1.585} \\
\hline & & Women & 3.25 & 0.890 & \\
\hline & \multirow{2}{*}{ Employment management } & Men & 3.59 & 0.800 & \multirow{2}{*}{0.846} \\
\hline & & Women & 3.43 & 0.732 & \\
\hline
\end{tabular}

${ }^{* *} p<0.01 ; M$, mean; S.D., standard deviation.

Table 4. Differences in human resource management by age

\begin{tabular}{|c|c|c|c|c|c|}
\hline Age & & & M & S.D. & $F$-value $(p)$ \\
\hline \multirow{24}{*}{$\begin{array}{l}\text { Human resources } \\
\text { management }\end{array}$} & \multirow{6}{*}{ Education management } & Teenager & $3.21 \mathrm{~B}$ & 0.818 & \multirow{6}{*}{$5.168^{* * *}$} \\
\hline & & $20 \mathrm{~s}$ & $3.48 \mathrm{AB}$ & 0.836 & \\
\hline & & $30 \mathrm{~s}$ & $3.76 \mathrm{~A}$ & 0.762 & \\
\hline & & $40 \mathrm{~s}$ & $3.88 \mathrm{~A}$ & 0.710 & \\
\hline & & 50 s or older & $3.86 \mathrm{~A}$ & 0.761 & \\
\hline & & Total & 3.55 & 0.827 & \\
\hline & \multirow{6}{*}{ Work management } & Teenager & $3.53 \mathrm{AB}$ & 0.797 & \multirow{6}{*}{$14.130^{* * *}$} \\
\hline & & 20 s & $3.29 \mathrm{~B}$ & 0.744 & \\
\hline & & $30 \mathrm{~s}$ & $3.73 \mathrm{AB}$ & 0.689 & \\
\hline & & $40 s$ & $3.91 \mathrm{~A}$ & 0.693 & \\
\hline & & 50 s or older & $3.87 \mathrm{~A}$ & 0.557 & \\
\hline & & Total & 3.41 & 0.760 & \\
\hline & \multirow{6}{*}{ Compensation management } & Teenager & $3.13 B$ & 0.765 & \multirow{6}{*}{$13.222^{* * *}$} \\
\hline & & $20 \mathrm{~s}$ & 3.15B & 0.860 & \\
\hline & & $30 \mathrm{~s}$ & $3.67 \mathrm{~A}$ & 0.863 & \\
\hline & & $40 \mathrm{~s}$ & $3.80 \mathrm{~A}$ & 0.767 & \\
\hline & & 50 s or older & $3.78 \mathrm{~A}$ & 0.423 & \\
\hline & & Total & 3.27 & 0.879 & \\
\hline & \multirow{6}{*}{ Employment management } & Teenager & $2.98 \mathrm{C}$ & 0.787 & \multirow{6}{*}{$7.079^{* * *}$} \\
\hline & & $20 \mathrm{~s}$ & $3.38 \mathrm{BC}$ & 0.735 & \\
\hline & & $30 \mathrm{~s}$ & $3.68 \mathrm{AB}$ & 0.733 & \\
\hline & & $40 \mathrm{~s}$ & $3.70 \mathrm{AB}$ & 0.658 & \\
\hline & & 50 s or older & $3.94 \mathrm{~A}$ & 0.512 & \\
\hline & & Total & 3.45 & 0.742 & \\
\hline
\end{tabular}

${ }^{* * *} p<0.001$; Duncan test results are A>B; M, mean; S.D., standard deviation. 
6-10명 34.4\%, 11-15명 22.9\%, 16-20명 7.0\%, 21명 이상

$9.4 \%$ 로 6-10명이 가장 높게 나타났다. 미용분야를 알아본 결과
헤어 $72.0 \%$, 메이크업 $3.4 \%$, 피부관리 $17.4 \%$, 네일아트 $4.0 \%$, 기타 $3.1 \%$ 로 헤어가 가장 높게 나타났다.

Table 5. Differences in human resource management by marital status

\begin{tabular}{|c|c|c|c|c|c|}
\hline \multicolumn{3}{|l|}{ Marital status } & $M$ & S.D. & $F$-value $(p)$ \\
\hline \multirow{16}{*}{$\begin{array}{l}\text { Human resources } \\
\text { management }\end{array}$} & \multirow{4}{*}{ Education management } & Single & $3.50 \mathrm{~A}$ & 0.825 & \multirow{4}{*}{$6.521^{* *}$} \\
\hline & & Married & $3.83 \mathrm{~A}$ & 0.792 & \\
\hline & & Divorced & $3.75 \mathrm{~A}$ & 0.820 & \\
\hline & & Total & 3.55 & 0.827 & \\
\hline & \multirow{4}{*}{ Work management } & Single & $3.33 B$ & 0.747 & \multirow{4}{*}{$22.207^{* * *}$} \\
\hline & & Married & $3.83 \mathrm{~A}$ & 0.698 & \\
\hline & & Divorced & $4.11 \mathrm{~A}$ & 0.414 & \\
\hline & & Total & 3.41 & 0.760 & \\
\hline & \multirow{4}{*}{ Compensation management } & Single & $3.18 \mathrm{~B}$ & 0.864 & \multirow{4}{*}{$26.395^{* * *}$} \\
\hline & & Married & $3.84 \mathrm{~A}$ & 0.738 & \\
\hline & & Divorced & $3.89 \mathrm{~A}$ & 0.849 & \\
\hline & & Total & 3.27 & 0.879 & \\
\hline & \multirow{4}{*}{ Employment management } & Single & $3.40 \mathrm{~A}$ & 0.726 & \multirow{4}{*}{$9.095^{* * *}$} \\
\hline & & Married & $3.75 \mathrm{~A}$ & 0.783 & \\
\hline & & Divorced & $3.44 \mathrm{~A}$ & 0.659 & \\
\hline & & Total & 3.45 & 0.742 & \\
\hline
\end{tabular}

${ }^{* *} p<0.01 ;{ }^{* * *} p<0.001$; Duncan test results are A>B; M, mean; S.D., standard deviation.

Table 6. Differences in human resource management by education level

\begin{tabular}{|c|c|c|c|c|c|}
\hline \multicolumn{2}{|l|}{ Education level } & & $M$ & S.D. & $F$-value $(p)$ \\
\hline \multirow{20}{*}{$\begin{array}{l}\text { Human resources } \\
\text { management }\end{array}$} & \multirow{5}{*}{ Education management } & Graduated from high school & $3.73 \mathrm{~A}$ & 0.839 & \multirow{5}{*}{$11.249^{* *}$} \\
\hline & & $\begin{array}{l}\text { Currently attending or graduated from } \\
\text { college }\end{array}$ & $3.75 \mathrm{~A}$ & 0.804 & \\
\hline & & $\begin{array}{l}\text { Currently attending or graduated from } \\
\text { university }\end{array}$ & $3.37 \mathrm{~B}$ & 0.813 & \\
\hline & & $\begin{array}{l}\text { Currently attending or graduated from } \\
\text { graduate school }\end{array}$ & $3.66 \mathrm{~A}$ & 0.748 & \\
\hline & & Total & 3.55 & 0.827 & \\
\hline & \multirow{5}{*}{ Work management } & Graduated from high school & $3.72 \mathrm{~A}$ & 0.779 & \multirow{5}{*}{$22.058^{* *}$} \\
\hline & & $\begin{array}{l}\text { Currently attending or graduated from } \\
\text { college }\end{array}$ & $3.56 \mathrm{~A}$ & 0.664 & \\
\hline & & $\begin{array}{l}\text { Currently attending or graduated from } \\
\text { university }\end{array}$ & $3.19 \mathrm{~B}$ & 0.746 & \\
\hline & & $\begin{array}{l}\text { Currently attending or graduated from } \\
\text { graduate school }\end{array}$ & $3.68 \mathrm{~A}$ & 0.709 & \\
\hline & & Total & 3.41 & 0.760 & \\
\hline & \multirow{5}{*}{ Compensation management } & Graduated from high school & $3.62 \mathrm{~A}$ & 0.943 & \multirow{5}{*}{$21.888^{* * *}$} \\
\hline & & $\begin{array}{l}\text { Currently attending or graduated from } \\
\text { college }\end{array}$ & $3.50 \mathrm{~A}$ & 0.841 & \\
\hline & & $\begin{array}{l}\text { Currently attending or graduated from } \\
\text { university }\end{array}$ & $3.02 \mathrm{~B}$ & 0.822 & \\
\hline & & $\begin{array}{l}\text { Currently attending or graduated from } \\
\text { graduate school }\end{array}$ & $3.47 \mathrm{~A}$ & 0.773 & \\
\hline & & Total & 3.27 & 0.879 & \\
\hline & \multirow{5}{*}{ Employment management } & Graduated from high school & $3.53 \mathrm{AB}$ & 0.791 & \multirow{5}{*}{$4.649^{* *}$} \\
\hline & & $\begin{array}{l}\text { Currently attending or graduated from } \\
\text { college }\end{array}$ & $3.56 \mathrm{~A}$ & 0.759 & \\
\hline & & $\begin{array}{l}\text { Currently attending or graduated from } \\
\text { university }\end{array}$ & $3.34 \mathrm{~B}$ & 0.712 & \\
\hline & & $\begin{array}{l}\text { Currently attending or graduated from } \\
\text { graduate school }\end{array}$ & $3.54 \mathrm{AB}$ & 0.702 & \\
\hline & & Total & 3.45 & 0.742 & \\
\hline
\end{tabular}

${ }^{* *} p<0.01 ;{ }^{* * *} p<0.001$; Duncan test results are A>B; M, mean; S.D., standard deviation. 


\section{2. 인적자원관리의 타당성 및 신뢰도}

인적자원관리 문항에 대해 요인분석을 이용한 타당성 검증결과
Table 2 와 같이 교육관리, 직무관리, 보상관리, 채용관리의 네 개의 요인이 도출되었다. Bartlett의 단위행렬 점검 결과 $\chi^{2}=7553.039$

Table 7. Differences in human resource management by post

\begin{tabular}{|c|c|c|c|c|c|}
\hline Post & & & $M$ & S.D. & $F$-value $(p)$ \\
\hline \multirow{24}{*}{$\begin{array}{l}\text { Human resources } \\
\text { management }\end{array}$} & \multirow{6}{*}{ Education management } & Intern (assistant) & $3.54 \mathrm{~B}$ & 0.846 & \multirow{6}{*}{$3.159^{*}$} \\
\hline & & Designer (working- level) & $3.46 \mathrm{~B}$ & 0.824 & \\
\hline & & Director (branch representative) & $3.88 \mathrm{~A}$ & 0.797 & \\
\hline & & Chairman (representative) & $3.71 \mathrm{AB}$ & 0.692 & \\
\hline & & Manager & $3.46 \mathrm{~B}$ & 0.763 & \\
\hline & & Total & 3.55 & 0.827 & \\
\hline & \multirow{6}{*}{ Work management } & Intern (assistant) & $3.30 \mathrm{~B}$ & 0.732 & \multirow{6}{*}{$10.955^{* * *}$} \\
\hline & & Designer (working- level) & 3.37B & 0.751 & \\
\hline & & Director (branch representative) & $3.80 \mathrm{~A}$ & 0.732 & \\
\hline & & Chairman (representative) & $3.91 \mathrm{~A}$ & 0.688 & \\
\hline & & Manager & $3.41 B$ & 0.812 & \\
\hline & & Total & 3.41 & 0.760 & \\
\hline & \multirow{6}{*}{ Compensation management } & Intern (assistant) & $3.10 \mathrm{C}$ & 0.850 & \multirow{6}{*}{$14.205^{* * *}$} \\
\hline & & Designer (working- level) & $3.27 \mathrm{BC}$ & 0.870 & \\
\hline & & Director (branch representative) & $3.82 \mathrm{~A}$ & 0.888 & \\
\hline & & Chairman (representative) & $3.84 \mathrm{~A}$ & 0.716 & \\
\hline & & Manager & $3.44 \mathrm{~B}$ & 0.741 & \\
\hline & & Total & 3.27 & 0.879 & \\
\hline & \multirow{6}{*}{ Employment management } & Intern (assistant) & $3.38 \mathrm{~B}$ & 0.769 & \multirow{6}{*}{$6.698^{* * *}$} \\
\hline & & Designer (working- level) & $3.40 \mathrm{~B}$ & 0.694 & \\
\hline & & Director (branch representative) & $3.83 \mathrm{~A}$ & 0.731 & \\
\hline & & Chairman (representative) & $3.77 \mathrm{~A}$ & 0.649 & \\
\hline & & Manager & $3.47 \mathrm{~B}$ & 0.664 & \\
\hline & & Total & 3.45 & 0.742 & \\
\hline
\end{tabular}

${ }^{*} p<0.05 ;{ }^{* * *} p<0.001$; Duncan test results are A>B $>C$; M, mean; S.D., standard deviation.

Table 8. Differences in human resource management by type of wage

\begin{tabular}{|c|c|c|c|c|c|}
\hline Type of wage & & & $M$ & S.D. & $F$-value $(p)$ \\
\hline \multirow{16}{*}{$\begin{array}{l}\text { Human resources } \\
\text { management }\end{array}$} & \multirow{4}{*}{ Education management } & Wage & $3.49 \mathrm{~A}$ & 0.821 & \multirow{4}{*}{$3.837^{*}$} \\
\hline & & Incentive & $3.66 \mathrm{~A}$ & 0.882 & \\
\hline & & Others & $3.72 \mathrm{~A}$ & 0.624 & \\
\hline & & Total & 3.55 & 0.827 & \\
\hline & \multirow{4}{*}{ Work management } & Wage & $3.28 \mathrm{~B}$ & 0.735 & \multirow{4}{*}{$24.891^{* * *}$} \\
\hline & & Incentive & $3.66 \mathrm{~A}$ & 0.750 & \\
\hline & & Others & $3.81 \mathrm{~A}$ & 0.685 & \\
\hline & & Total & 3.41 & 0.760 & \\
\hline & \multirow{4}{*}{ Compensation management } & Wage & $3.10 \mathrm{~B}$ & 0.826 & \multirow{4}{*}{$33.431^{* * *}$} \\
\hline & & Incentive & $3.61 \mathrm{~A}$ & 0.896 & \\
\hline & & Others & $3.78 \mathrm{~A}$ & 0.781 & \\
\hline & & Total & 3.27 & 0.879 & \\
\hline & \multirow{4}{*}{ Employment management } & Wage & 3.38B & 0.724 & \multirow{4}{*}{$7.640^{* *}$} \\
\hline & & Incentive & $3.56 \mathrm{AB}$ & 0.794 & \\
\hline & & Others & $3.73 \mathrm{~A}$ & 0.627 & \\
\hline & & Total & 3.45 & 0.742 & \\
\hline
\end{tabular}

${ }^{*} p<0.05 ;{ }^{* *} p<0.01 ;{ }^{* * *} p<0.001$; Duncan test results are A>B; M, mean; S.D., standard deviation. 
$(\mathrm{df}=136, \mathrm{Sig}=0.000), \mathrm{KMO}$ 값 0.930 으로 나타났으며, 공통성은 0.582 이상으로 나타났다.
요인분석 결과 도출된 네 개의 요인이 전체 분산의 $72.1 \%$ 이상 설명되고 있는 것으로 나타났다.

Table 9. Differences in human resource management by beauty career

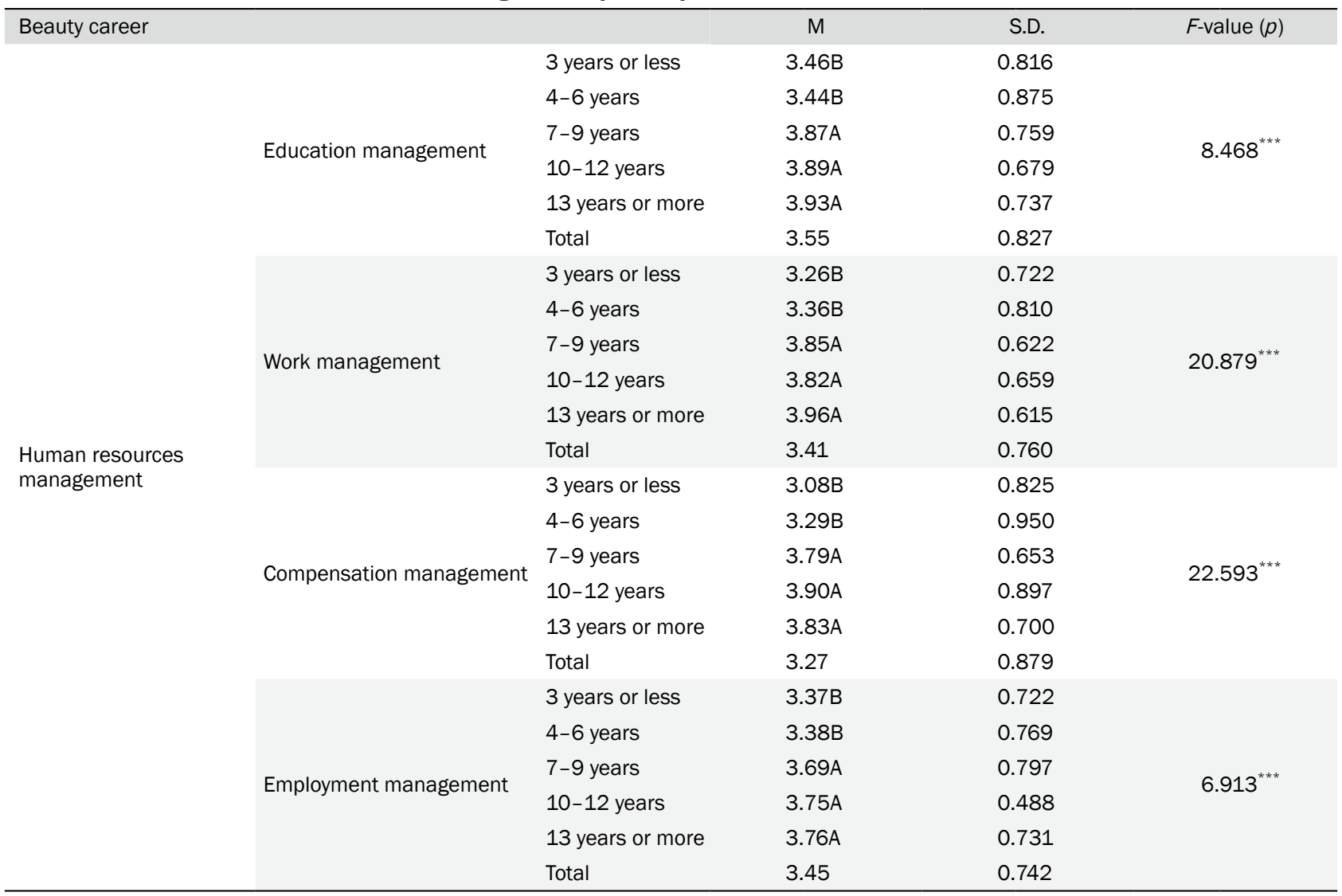

${ }^{* * *} p<0.001$; Duncan test results are A>B; M, mean; S.D., standard deviation.

Table 10. Differences in human resource management by type of company

\begin{tabular}{|c|c|c|c|c|c|}
\hline Type of company & & & $M$ & S.D. & $F$-value $(p)$ \\
\hline \multirow{16}{*}{$\begin{array}{l}\text { Human resources } \\
\text { management }\end{array}$} & \multirow{4}{*}{ Education management } & Franchise & $3.69 \mathrm{~A}$ & 0.804 & \multirow{4}{*}{$15.347^{* * *}$} \\
\hline & & Private enterprise & 3.33B & 0.812 & \\
\hline & & Others & $3.58 \mathrm{AB}$ & 0.899 & \\
\hline & & Total & 3.55 & 0.827 & \\
\hline & \multirow{4}{*}{ Work management } & Franchise & 3.42 & 0.715 & \multirow{4}{*}{0.847} \\
\hline & & Private enterprise & 3.41 & 0.822 & \\
\hline & & Others & 3.22 & 0.769 & \\
\hline & & Total & 3.41 & 0.760 & \\
\hline & \multirow{4}{*}{ Compensation management } & Franchise & 3.29 & 0.877 & \multirow{4}{*}{0.265} \\
\hline & & Private enterprise & 3.26 & 0.882 & \\
\hline & & Others & 3.17 & 0.896 & \\
\hline & & Total & 3.27 & 0.879 & \\
\hline & \multirow{4}{*}{ Employment management } & Franchise & $3.57 \mathrm{~A}$ & 0.707 & \multirow{4}{*}{$15.676^{* * *}$} \\
\hline & & Private enterprise & $3.25 \mathrm{~B}$ & 0.755 & \\
\hline & & Others & $3.49 A B$ & 0.722 & \\
\hline & & Total & 3.45 & 0.742 & \\
\hline
\end{tabular}

${ }^{* * *} p<0.001$; Duncan test results are A>B; M, mean; S.D., standard deviation. 
인적자원관리에 대한 신뢰성 검증 결과, 신뢰도 계수인 Cronbach's $\alpha$ 는 0.834-0.900으로 높게 나타나, 신뢰성에는 문 제가 없는 것으로 나타났다. 요인별로 살펴보면, 교육관리 0.900 , 직무관리 0.870 , 보상관리 0.893 , 채용관리 0.834 로 나타났다. 이러한 결과는 인적자원관리를 근로시간, 급여수준, 교육횟수의 세 개의 요인으로 도출된 Chai \& Park (2017)의 연구와 유사함을 확인하였다.

\section{3. 미용서비스업 종사자의 특성에 따른 인적자원관리}

미용서비스업 종사자의 특성(성별, 연령, 결혼여부, 학력, 직급, 급여형태, 근무경력, 회사형태, 직원 수, 전문분야)에 따른 인적자 원관리의 차이를 알아보기 위해 독립표본 $t$-test, 일원변량분석 (one way ANOVA)을 실시한 결과는 다음과 같다. 사후검증은 던 컨테스트를 사용하였다.

\section{1) 성별에 따른 인적자원관리의 차이}

직무관리 요인에서 Table 3 와 같이 통계적으로 유의미한 차이 를 보였고 $(p<0.01)$, 남자의 평균이 여자보다 높게 나타났다.

2) 연령에 따른 인적자원관리의 차이
교육관리, 직무관리, 보상관리, 채용관리 요인에서 Table 4와 같이 통계적으로 유의미한 차이를 보였다 $(p<0.001)$. 교육관리, 직 무관리, 보상관리 요인은 40 대의 평균이 가장 높게 나타났고 채용 관리 요인은 50 대의 평균이 가장 높게 나타났다.

3) 결혼여부에 따른 인적자원관리의 차이

교육관리 요인에서 Table 5 와 같이 통계적으로 유의미한 차이 를 보였고 $(p<0.01)$, 직무관리, 보상관리, 채용관리 요인에서 통계 적으로 유의미한 차이를 보였다 $(p<0.001)$. 교육관리, 채용관리 요 인은 기혼의 평균이 미혼의 평균에 비해 상대적으로 높게 나타났 으나 던컨테스트 결과 집단으로 분류되지 않았다. 직무관리, 보상 관리 요인은 이혼의 평균이 미혼의 평균에 비해 상대적으로 높게 나타났다.

\section{4) 학력에 따른 인적자원관리의 차이}

교육관리, 직무관리, 보상관리 요인에서 Table 6와 같이 통계적 으로 유의미한 차이를 보였고 $(p<0.001)$, 채용관리 요인에서 통계 적으로 유의미한 차이를 보였다 $(p<0.01)$, 교육관리, 채용관리 요 인은 전문대학 재학/졸업의 평균이 가장 높게 나타났고 직무관리, 보상관리 요인은 고등학교 졸업의 평균이 가장 높게 나타났다.

\section{Table 11. Differences in human resource management by No. of employees}

\begin{tabular}{|c|c|c|c|c|c|}
\hline \multicolumn{3}{|l|}{ No. of employees } & \multirow{2}{*}{$\begin{array}{c}M \\
3.37 \mathrm{C}\end{array}$} & \multirow{2}{*}{$\begin{array}{c}\text { S.D. } \\
0.791\end{array}$} & \multirow[t]{2}{*}{$F$-value $(p)$} \\
\hline \multirow{11}{*}{$\begin{array}{l}\text { Human resources } \\
\text { management }\end{array}$} & \multirow{6}{*}{ Education management } & 5 persons or less & & & \\
\hline & & 6-10 persons & $3.57 \mathrm{BC}$ & 0.833 & \multirow{5}{*}{$4.319^{*}$} \\
\hline & & 11-15 persons & $3.63 \mathrm{AB}$ & 0.836 & \\
\hline & & 16-20 persons & $3.86 \mathrm{~A}$ & 0.840 & \\
\hline & & 21 persons or more & $3.54 \mathrm{BC}$ & 0.795 & \\
\hline & & Total & 3.55 & 0.827 & \\
\hline & \multirow{6}{*}{ Work management } & 5 persons or less & $3.47 \mathrm{~A}$ & 0.835 & \multirow{6}{*}{$2.422^{*}$} \\
\hline & & 6-10 persons & $3.42 \mathrm{~A}$ & 0.724 & \\
\hline & & $11-15$ persons & $3.43 \mathrm{~A}$ & 0.708 & \\
\hline & & 16-20 persons & $3.41 \mathrm{~A}$ & 0.852 & \\
\hline & & 21 persons or more & 3.14B & 0.680 & \\
\hline \multirow{13}{*}{$\begin{array}{l}\text { Human resources } \\
\text { management }\end{array}$} & & Total & 3.41 & 0.760 & \\
\hline & \multirow{6}{*}{ Compensation management } & 5 persons or less & $3.30 \mathrm{~A}$ & 0.883 & \multirow{6}{*}{$2.520^{*}$} \\
\hline & & 6-10 persons & $3.28 \mathrm{~A}$ & 0.866 & \\
\hline & & 11-15 persons & $3.35 \mathrm{~A}$ & 0.887 & \\
\hline & & 16-20 persons & $3.33 \mathrm{~A}$ & 0.834 & \\
\hline & & 21 persons or more & $2.96 \mathrm{~B}$ & 0.885 & \\
\hline & & Total & 3.27 & 0.879 & \\
\hline & \multirow{6}{*}{ Employment management } & 5 persons or less & $3.26 C$ & 0.718 & \multirow{6}{*}{$5.735^{* * *}$} \\
\hline & & $6-10$ persons & $3.49 B$ & 0.724 & \\
\hline & & $11-15$ persons & $3.54 \mathrm{AB}$ & 0.683 & \\
\hline & & 16-20 persons & $3.72 \mathrm{~A}$ & 0.725 & \\
\hline & & 21 persons or more & $3.36 \mathrm{BC}$ & 0.900 & \\
\hline & & Total & 3.45 & 0.742 & \\
\hline
\end{tabular}

${ }^{*} p<0.05 ;{ }^{* *} p<0.01 ;{ }^{* * *} p<0.001$; Duncan test results are A $>B>C$; M, mean; S.D., standard deviation. 
5) 직급에 따른 인적자원관리의 차이

교육관리 요인에서 Table 7과 같이 통계적으로 유의미한 차이 를 보였고 $(p<0.05)$, 직무관리, 보상관리, 채용관리 요인에서 통계 적으로 유의미한 차이를 보였다 $(p<0.001)$. 교육관리, 채용관리 요 인은 실장(점장)의 평균이 가장 높게 나타났고 직무관리, 보상관 리 요인은 원장(대표)의 평균이 가장 높게 나타났다. 이러한 결과 는 Kim et al. (2017)의 직급에 따른 인적자원관리와 조직몰입의 차이를 분석하여 인적자원하위 요인에서 모두 통계적으로 유의한 차이를 보인 것과 유사함을 확인하였다.

\section{6) 급여형태에 따른 인적자원관리의 차이}

교육관리 요인에서 Table 8과 같이 통계적으로 유의미한 차이 를 보였고 $(p<0.05)$, 직무관리, 보상관리 요인에서 통계적으로 유 의미한 차이를 보였으며 $(p<0.001)$, 채용관리 요인에서 통계적으 로 유의미한 차이를 보였다 $(p<0.01)$. 교육관리 요인은 기타의 평 균이 가장 높게 나타났으나 던컨테스트 결과 집단으로 분류되지 않았다. 직무관리, 보상관리, 채용관리 요인은 기타의 평균이 가 장 높게 나타났고 급여의 평균이 가장 낮게 나타났다.
7) 근무경력에 따른 인적자원관리의 차이

교육관리, 직무관리, 보상관리, 채용관리 요인에서 Table 9과 같이 통계적으로 유의미한 차이를 보였다 $(p<0.001)$. 교육관리, 직 무관리, 채용관리 요인은 13 년 이상의 평균이 가장 높게 나타났고 보상관리 요인은 10 년에서 12 년 이상의 평균이 가장 높게 나타났 다.

\section{8) 회사형태에 따른 인적자원관리의 차이}

교육관리, 채용관리 요인에서 Table 10과 같이 통계적으로 유 의미한 차이를 보였다 $(p<0.001)$. 교육관리, 채용관리 요인 모두 프랜차이즈의 평균이 가장 높게 나타났다.

\section{9) 직원 수에 따른 인적자원관리의 차이}

교육관리 요인에서 Table 11 과 같이 통계적으로 유의미한 차이 를 보였고 $(p<0.01)$, 직무관리, 보상관리 요인에서 통계적으로 유 의미한 차이를 보였으며 $(p<0.05)$, 채용관리 요인에서 통계적으로 유의미한 차이를 보였다 $(p<0.001)$. 교육관리 요인은 16 명에서 20 명의 평균이 가장 높게 나타났고 직무관리 요인은 5 명 이하의 평 균이 가장 높게 나타났다. 보상관리 요인은 11 명에서 15 명의 평

Table 12. Differences in human resource management by beauty field

\begin{tabular}{|c|c|c|c|c|c|}
\hline Beauty field & & & $M$ & S.D. & $F$-value $(p)$ \\
\hline \multirow{24}{*}{$\begin{array}{l}\text { Human resources } \\
\text { management }\end{array}$} & \multirow{6}{*}{ Education management } & Hair & $3.64 \mathrm{~A}$ & 0.819 & \multirow{6}{*}{$8.473^{* * *}$} \\
\hline & & Makeup & $3.33 \mathrm{AB}$ & 0.940 & \\
\hline & & Skin care & $3.18 \mathrm{~B}$ & 0.734 & \\
\hline & & Nail art & $3.65 \mathrm{~A}$ & 0.731 & \\
\hline & & Others & $3.61 \mathrm{~A}$ & 0.947 & \\
\hline & & Total & 3.55 & 0.827 & \\
\hline & \multirow{6}{*}{ Work management } & Hair & $3.47 \mathrm{~A}$ & 0.738 & \multirow{6}{*}{$11.414^{* * *}$} \\
\hline & & Makeup & $3.52 \mathrm{~A}$ & 0.884 & \\
\hline & & Skin care & $3.02 B$ & 0.741 & \\
\hline & & Nail art & $3.79 \mathrm{~A}$ & 0.611 & \\
\hline & & Others & $3.52 \mathrm{~A}$ & 0.686 & \\
\hline & & Total & 3.41 & 0.760 & \\
\hline & \multirow{6}{*}{ Compensation management } & Hair & $3.31 \mathrm{AB}$ & 0.884 & \multirow{6}{*}{$4.504^{* *}$} \\
\hline & & Makeup & $3.44 \mathrm{~A}$ & 1.048 & \\
\hline & & Skin care & $3.00 \mathrm{~B}$ & 0.814 & \\
\hline & & Nail art & $3.59 \mathrm{~A}$ & 0.727 & \\
\hline & & Others & $3.47 \mathrm{~A}$ & 0.807 & \\
\hline & & Total & 3.27 & 0.879 & \\
\hline & \multirow{6}{*}{ Employment management } & Hair & $3.44 \mathrm{~A}$ & 0.758 & \multirow{6}{*}{0.179} \\
\hline & & Makeup & $3.47 \mathrm{~A}$ & 0.627 & \\
\hline & & Skin care & $3.43 \mathrm{~A}$ & 0.696 & \\
\hline & & Nail art & $3.55 \mathrm{~A}$ & 0.698 & \\
\hline & & Others & $3.47 \mathrm{~A}$ & 0.828 & \\
\hline & & Total & 3.45 & 0.742 & \\
\hline
\end{tabular}

${ }^{* *} p<0.01 ;{ }^{* * *} p<0.001$; Duncan test results are A>B; M, mean; S.D., standard deviation. 
균이 가장 높게 나타났고 채용관리 요인은 16 명에서 20 명의 평균 이 가장 높게 나타났다.

\section{0) 전문분야에 따른 인적자원관리의 차이}

교육관리, 직무관리 요인에서 Table 12 와 같이 통계적으로 유 의미한 차이를 보였고 $(p<0.001)$, 보상관리 요인에서 통계적으로 유의미한 차이를 보였다 $(p<0.01)$. 이는 Lee \& Kim (2014)의 연 구에서 보상제도가 직무만족도에 정(+)의 영향을 미친다는 결과 와 유사함을 확인하였다. 교육관리, 보상관리 요인은 네일아트의 평균이 가장 높게 나타났고 직무관리 요인은 기타, 메이크업의 평 균이 가장 높게 나타났다.

\section{Conclusion}

첫째, 조사대상의 일반적 특성을 알아본 결과, 성별은 여자, 연 령은 20 대, 결혼여부는 미혼, 학력은 대학교 재학/졸업, 직급은 인턴(어시스트), 급여형태는 급여, 미용경력은 3 년 이하, 회사형 태는 프랜차이즈, 직원 수는 6-10명, 미용분야는 헤어가 가장 높 게 나타났다.

둘째, 인적자원관리의 타당도 및 신뢰도를 알아본 결과, 교육관 리, 직무관리, 보상관리, 채용관리의 네 개의 요인으로 도출되었 다.

셋째, 미용서비스업 종사자의 특성에 따른 인적자원관리의 차 이를 알아본 결과, 인적자원관리는 성별, 연령, 결혼여부, 학력, 직급, 급여형태, 근무경력, 회사형태, 직원 수, 전문분야에 따라 유의미한 차이가 있는 것으로 나타났다. 연령과 근무경력이 높아 짐에 따라 인적자원관리의 차이가 높게 나타난 것은 미용서비스업 은 처음 시작하는 단계는 힘들지만 일을 할수록 근무환경이 좋아 지는 것이라 판단된다. 이는 반대로 연령이 낮은 미용서비스업을 처음 시작하는 단계의 종사자들의 인적자원관리가 더욱 활발히 이 루어져야 한다는 것을 보여주고 있다.

이에 미용서비스업에서는 조직의 목표달성을 위하여 종사자의 특성을 고려한 체계적인 인적자원관리를 계획하고 진행하여야 할 것으로 사료된다.

\section{References}

Bae J, Sa J. The effects of human resource management systems on organizational performance. Korean Journal of Management, 11: 133-169, 2003.

Chai CO, Park YJ. A study on the relationship between performance of small $\cdot$ medium enterprises and human resource management: focused on root manufacturing industry. The Journal of Humanities and Social Sciences, 8: 633-652, 2017.

Chang YS. Effect of justice-oriented human resource management on gender equality organizational culture. The Journal of Professional Management, 21: 169-187, 2018.

Chae JS, Kim CJ. The impact of strategic human resource management on management performance through organizational competence. Journal of Human Resource Management Research, 23: 143-174, 2019.

Ha SW, Shim DS. A study on the relationship between high-commitment human resource management and firm performance: mediating roles of exploitation and exploration. Journal of Human Resource Management Research, 20: 133-155, 2013.

Kim JH, Seo HS, Lee EH. The effect of human resource management on the organizational commitment of the beauty industry professionals. Journal of the Korean Society of Design Culture, 23: 223-234, 2017.

Kim JK, Bae SR. A study on the relationship between human resource management practices and corporate financial performance. Journal of Human Resource Management Research, 13: 57-78, 2006.

Lee $\mathrm{DH}, \mathrm{Kim} \mathrm{BH}$. An effect on satisfaction with duty, directivity to customers, and outcome of management of compensation system and duty education over golf workers. Journal of Golf Studies, 8: 81-90, 2014.

Lim YK, Park EJ. Effects of organizational identification on organizational phase and relative deprivation of beauticians. Asian Journal of Beauty and Cosmetology, 15: 204-213, 2017.

$\mathrm{Na}$ IG. The analysis on the effect of training on HR outcomes and organizational outcomes. Journal of Human Resource Management Research, 17: 39-56, 2010.

Park SJ. Mediating effects of organizational commitment on the relationship between beauty industry managers' leadership and customer orientation. Asian Journal of Beauty and Cosmetology, 16: 255-265, 2018.

Park OW, Cha JS. The perception of HRM practices and creative performance: moderating effect of motivation preference. The Korean Journal of Human Resources Development Quarterly, 20: 87-111, 2018.

Song ER, Park KH, Moon JS. The moderating effects of job 
embeddedness in the relationship between strategic human resource management and job competence, turnover intention. Korean Journal of Resources Development, 19: 73-107, 2016.

Yoo BH, Kim DJ. Influence of high commitment human resource management on firm performance: consistency hypothesis and mediating effect of employee's perception. Journal of Human Resource Management Research, 16: 195-219, 2012. 


\section{국문초록}

\section{미용서비스업 종사자의 특성에 따른 인적자원관리 연구}

박정은 ${ }^{1}$, 유애진 ${ }^{2}$, 박은준 ${ }^{1 *}$

${ }^{1}$ 서경대학교 헤어·메이크업디자인학과, 서울, 한국

${ }^{2}$ 숙명여자대학교 헬스산업학과, 서울, 한국

목적: 본 연구는 미용서비스업 종사자의 특성에 따른 인적자원관리 연구 알아보고자 한다. 방법: 미용서비스업 종사자를 대상으로 자료를 수집하였고, Statistical Package for the Social Sciences (SPSS) 22.0을 이용하여 분석하였다. 분석방법은 빈도분석, 요인분 석, 신뢰도분석, 독립표본 $t$-test, 일원변량분석(one way ANOVA)이 사용되었다. 결과: 인적자원관리는 성별, 연령, 결혼여부, 학 력, 직급, 급여형태, 근무경력, 회사형태, 직원 수, 전문분야에 따라 유의미한 차이가 있는 것으로 나타났다. 결론: 본 연구결과가 미 용서비스업의 발전을 위한 기초자료로 활용되기를 바라며, 미용서비스업에서는 조직의 목표달성을 위하여 종사자의 특성을 고려한 체계적인 인적자원관리를 계획하고 진행하여야 할 것으로 사료된다.

핵심어: 미용, 서비스업, 인적자원관리, 미용서비스업 종사자, 특성

\section{참고문헌}

김종관, 배상림. 인적자원관리활동과 기업 재무성과와의 관계에 관한 연구. 인적자원관리연구, $13: 57-78,2006$.

김지현, 서현숙, 이은희. 뷰티산업종사자의 인적자원관리가 조직몰입에 미치는 영향. 한국디자인문화학회지, $23: 223-$ $234,2017$.

나인강. 기업의 훈련이 근로자의 인적자원성과 및 기업성과에 미치는 영향. 인적자원관리연구, 17: 39-56, 2010.

박선주. 미용산업 경영자의 리더십과 고객지향성 관계에 대한 조직몰입의 매개효과. 아시안뷰티화장품학술지, $16: 255-$

$265,2018$.

박오원, 차종석. 인적자원관리 제도에 대한 인식과 창의적 성과 간의 관계: 동기부여 선호도의 조절효과. $H R D$ 연구, 20 :

87-111, 2018.

배종석, 사정혜. 인적자원관리와 조직성과에 대한 실증연구. 인사조직연구, 11: 133-169, 2003.

송은란, 박계홍, 문재승. 전략적 인적자원관리와 직무수행역량 및 이직의도의 관계에서 직무배태성의 조절효과. 인적자원 개발연구, 19: 73-107, 2016.

유병흥, 김동주. 헌신형 인적자원관리와 기업성과의 관계: 일관성 가설과 조직구성원 인식의 매개효과를 중심으로. 인적자 원관리연구, 16: 195-219, 2012.

이동현, 김봉현. 골프장 종사자들의 보상제도와 직무교육이 직무만족, 고객지향성 및 경영성과에 미치는 영향. 골프연구, 8: 81-90, 2014.

임윤경, 박은준. 미용종사자의 조직 동일시가 조직위상과 상대적 박탈감에 미치는 영향. 아시안뷰티화장품학술지, 15 : 204-213, 2017.

장용선. 공정성 중시 인적자원관리가 성 평등 조직문화에 미치는 영향. 전문경영인연구, 21: 169-187, 2018.

채주석, 김찬중. 전략적 인적자원관리가 조직역량을 통해 경영성과에 미치는 영향. 인적자원관리연구, $23: 143-174$, 2019 .

채창옥, 박영주. 중소기업의 성과와 인적자원관리 간 관계에 관한 연구: 뿌리산업체를 중심으로. 인문사회 $21,8: 633-$ 652, 2017.

하성욱, 심덕섭. 고몰입형 인적자원관리와 경영성과 간의 관계에 관한 연구. 인적자원관리연구, $20: 133-155,2013$. 


\section{中文摘要}

\section{根据美容服务工作者的特性研究人力资源管理}

朴貞恩 ${ }^{1}$, 劉愛眞 $^{2}$, 朴銀俊 $^{*}$

${ }^{1}$ 西京大学美发美容设计科, 首尔, 韩国

2淑明女子大学健康产业学科, 首尔, 韩国

目的: 本研究以美容工作者的特点为基础, 研究美容服务业的人力资源管理。方法: 研究对象来自美容服务行从 事者, 并使用社会科学统计软件包（SPSS）22.0进行分析。频率分析, 因子分析, 可靠性分析, 独立样本t检验 和单向ANOVA用于数据分析。结果: 基于性别, 年龄, 婚姻状况, 教育程度, 职位, 工资, 工作经历, 公司类 型, 员工人数和专业, 人力资源管理存在显着差异。结论: 研究结果可作为美容服务业发展的基础数据。在美容 服务行业，系统的人力资源管理应该基于工作者的特点，并进行规划和管理，以实现组织目标。

关键词: 美容, 服务业，人力资源管理，美容服务业从事者，特性 
